\title{
Chromium and Zinc Speciation in Airborne Particulate Matter Collected in Ulaanbaatar, Mongolia, by X-Ray Absorption Near-edge Structure Spectroscopy
}

\author{
Gerelmaa Gunchin ${ }^{1 *}$, Janos Osan ${ }^{2}$, Alessandro Migliori ${ }^{3}$, Dagva Shagjjamba ${ }^{4}$, \\ Christina Streli ${ }^{1}$
}

${ }^{1}$ Vienna University of Technology, Atominstitut, Vienna, Austria

2 Environmental Physics Department, Centre for Energy Research, Budapest, Hungary

${ }^{3}$ Nuclear Science and Instrumentation Laboratory, Physics section, IAEA, Seibersdorf, Austria

${ }^{4}$ Nuclear Research Center, National University of Mongolia, Ulaanbaatar, Mongolia

\section{ABSTRACT}

This study examined the chemical speciation of atmospheric particulate matter (PM) samples collected in Ulaanbaatar, Mongolia. The health effects of atmospheric aerosol depend on the particles' size distribution, elemental composition and chemical species as well as other factors, which vary according to the pollution sources and meteorological conditions. Employing the International Atomic Energy Agency (IAEA) supported X-ray fluorescence (XRF) beamline at Elettra Sincrotrone Trieste, Italy, we used a small incidence angle for the synchrotron emission radiation in this ultra-high-vacuum environment to analyze the fine and the coarse mode $\left(\mathrm{PM}_{2.5}\right.$ and $\mathrm{PM}_{2.5-10}$, respectively) through $\mathrm{X}$-ray absorption near-edge structure (XANES) spectroscopy, which was applied to the K-edges of the chromium ( $\mathrm{Cr}$ ) and zinc $(\mathrm{Zn})$ in PM samples selected via energy-dispersive XRF (EDXRF) analysis for their high concentrations of these transition metals. The spectroscopic results identified trivalent chromium sulfate $\left[\mathrm{Cr}_{2}\left(\mathrm{SO}_{4}\right)_{3}\right]$ and chromium oxide $\left(\mathrm{Cr}_{2} \mathrm{O}_{3}\right)$ compounds as the major chemical forms of $\mathrm{Cr}$ in both the coarse and the fine PM fraction. Furthermore, both fractions contained abundances of sulfate $\left(\mathrm{ZnSO}_{4}\right)$ and silicate $\left(\mathrm{Zn}_{2} \mathrm{SiO}_{4}\right)$ compounds, but only the fine mode contained $\mathrm{Zn}$ oxalate $\left(\mathrm{ZnC}_{2} \mathrm{O}_{4}\right)$, whereas only the coarse mode contained $\mathrm{Zn}$ chloride $\left(\mathrm{ZnCl}_{2}\right)$. These $\mathrm{Cr}$ and $\mathrm{Zn}$ species seemed to originate from local anthropogenic sources, e.g., combustion products or traffic-related resuspended road dust.

Our findings, which are based on the first chemical speciation analysis from Ulaanbaatar,

Received: January 29, 202

Revised: April 29, 2021

Accepted: May 6, 2021

provide insight into the physiochemical characteristics of atmospheric aerosols as well as information on the potential sources of $\mathrm{Cr}$ and $\mathrm{Zn}$ species bound to fine and coarse PM.

${ }^{*}$ Corresponding Author:

g.gerelmaa@gmail.com

Keywords: XANES, Cr and Zn speciation, Atmospheric PM, Ulaanbaatar

\section{Publisher:}

Taiwan Association for Aerosol Research

ISSN: $1680-8584$ print

ISSN: 2071-1409 online

(c) Copyright: The Author(s). This is an open access article distributed under the terms of the Creative Commons Attribution License (CC BY 4.0), which permits unrestricted use, distribution, and reproduction in any medium, provided the original author and source are cited.

\section{INTRODUCTION}

Atmospheric particulate matter (PM) originating from anthropogenic and natural sources represents a common concern worldwide due to their associations with climate change, atmospheric visibility and more importantly with human health (Fittschen, 2014). The size of PM is considered significant since an epidemiological study revealed a correlation between PM mass of coarse particles with diameter of less than $10 \mu \mathrm{m},\left(\mathrm{PM}_{10-2.5}\right)$ and especially fine particles with diameter of less than $2.5 \mu \mathrm{m}\left(\mathrm{PM}_{2.5}\right)$ and a variety of adverse effects on health (Cruz et al., 2015). Causes and consequences of PM depend on the size distribution, concentration level, elemental composition and especially on the type of chemical species. These features characterize the toxicity of PM, including physical and chemical properties and this might vary from one place to another, 
characteristics of an area and contributing sources. Therefore, chemical speciation studies are important for the assessment of the toxicity of certain elements, particularly of heavy metals (Osan et al., 2010), as well as for the identification of PM sources.

X-ray absorption near-edge structure (XANES) spectrometry is one of the most suitable techniques to characterize different oxidation and chemical states of elements in atmospheric PM samples. Other techniques, such as ultraviolet-visible (UV-Vis) spectroscopy, inductively coupled plasma mass spectrometry and X-ray emission techniques, can measure only the total concentration of the element and require either a wet extraction or separation step for the speciation analysis (Ashley et al., 2003; Unceta et al., 2010). However, the experimental conditions adopted for the extraction may significantly influence the reliability of the measurement results (Pettine and Capri, 2005). Great advantages of XANES rely on the fact that it does not require any chemical pretreatment of the sample and can distinguish between different compounds of the same metal, including different oxidation states (e.g., $\mathrm{Cr}(\mathrm{VI}), \mathrm{Cr}(\mathrm{III})$, and $\mathrm{Cr}(0)$ ) as well as different compounds with the same oxidation state (e.g., $\mathrm{Cr}_{2} \mathrm{O}_{3}$ vs. $\mathrm{Cr}(\mathrm{OH})_{3}$ ) (Werner et al., 2007). Moreover, XANES allows nondestructive speciation of metals in solid samples, even for minor or trace concentrations $(<1 \%)$ (Osan et al., 2010).

The X-ray absorption measurements require an excitation source with high monochromaticity and energy tunability to scan with fine energy steps the selected absorption edge of the probed element and reveal the fine structure. When the probed element is available only in minor/trace amounts, the high intensity is an additional strict requirement for the X-ray source to allow short measuring times. Synchrotron radiation is optimally suitable for such studies, when using a double-crystal monochromator providing a resolving power $\triangle E / E$ better than $10^{-4}$.

A number of studies have been published on chromium and zinc speciation of airborne PM samples by XANES. Ohta et al. (2006) examined the variation of chemical compositions and speciation of $\mathrm{Zn}$ and other elements in different particle size aerosols in aeolian dust during their transportation from China to Japan. The results suggested that $\mathrm{Zn}$ originated primarily from crustal aerosols during the dust event, except for that in fine grains, and that the fraction of anthropogenic materials increased from $40 \%$ to $80 \%$, concomitant with decreasing particle size. Wang et al. (2007) also applied XANES to $\mathrm{Zn}, \mathrm{Cr}$ and other metals on two fractions of aerosol samples from different sites of Shanghai, China. Close to iron and steel industrial area, the main chemical components of $\mathrm{Cr}$ in PM were chromite and oxides of trivalent chromium. Werner et al. (2007) studied Cr speciation in three different areas of north California, USA. For every sampling station, trivalent chromium oxides, $\mathrm{Cr}$-Fe and chromite-like phase were found to be the dominant species, while some reduced $\mathrm{Cr}$ species (i.e., $\mathrm{Cr}(0)$ or $\mathrm{Cr}_{3} \mathrm{C}_{2}$ ) were also identified as minor chemical components. $\mathrm{Cr}(\mathrm{VI})$ containing particles were only found at the site of the most urban character. Similarly, in Saudi Arabia, the dominant state of chromium in two-fractioned aerosol samples was the trivalent chromium oxide, while $\mathrm{Cr}(\mathrm{VI})$ was a minor contribution with range of 7-9\% (Shaltout et al., 2018). Many other studies were successfully conducted using XANES analysis for elemental speciation (Huggins et al., 2000; Boman et al., 2004; Galbreath and Zygarlicke, 2004; Goodzari et al., 2008).

The aim of the present paper is to gain information about chemical speciation of two elements of interest $\left(\mathrm{Cr}\right.$ and $\mathrm{Zn}$ ) in atmospheric $\mathrm{PM}_{2.5}$ and $\mathrm{PM}_{10-2.5}$ samples, which were collected from Ulaanbaatar, the capital city of Mongolia. These two transition metals were selected because of their importance and abundance in the collected atmospheric samples. Acquiring knowledge on $\mathrm{Cr}$ and $\mathrm{Zn}$ speciation in local atmospheric PM is important for the assessment of toxicity as well as for better characterization of their corresponding sources.

The present study provided enhanced insights in Ulaanbaatar's size-fractioned atmospheric aerosols' physiochemical nature. It delivers further information on the potential origin and contributing pollution sources of the selected elements through their speciation for the first time.

\section{MATERIALS AND METHODS}

\subsection{Sample Collection}

Atmospheric particles were collected on polycarbonate filters at the air quality monitoring site, $4 \mathrm{~km}$ east of the center of Ulaanbaatar (latitude $47^{\circ} 55^{\prime}$, longitude $106^{\circ} 55^{\prime}, 1300 \mathrm{~m}$ above sea level). More information about the sampling site is described in Gunchin et al. (2019). In total, 52 samples 
were collected, twice a week (every Monday and Thursday) throughout the period June 2016January 2017. A GENT sampler (Maenhaut et al., 1993) was used, comprising a $\mathrm{PM}_{10}$ impactortype size-selective inlet and a stacked filter unit (SFU) assembly connected to a pump and an air flow meter. The SFU is made up of two filters arranged sequentially, allowing the fractionation of particles on two different stages. The top filter (pore size $8 \mu \mathrm{m}$ ) collected the coarse $\left(\mathrm{PM}_{10-2.5}\right)$ particle fraction and the bottom filter (pore size $0.4 \mu \mathrm{m}$ ) collected the fine $\left(\mathrm{PM}_{2.5}\right)$ particle fraction.

The sampler was operated with the average flow rate of $16.0 \mathrm{~L} \mathrm{~min}^{-1}$ in alternating $30 \mathrm{~min}$ onand 30 min off-periods over the course of the 24 hours as to provide a representative sample for the whole day. However, due to atmospheric conditions and the level of the pollution of that sampling day, it was not possible to collect over the entire 24 hours as high pollution resulted in clogging of the filters. Due to this fact, the flow rate of the sampler was varying between 18.014.0 $\mathrm{L} \mathrm{min}^{-1}$ and averaging and calculations of the total air volume for each sample measurement were done accordingly. Gravimetric masses of PM samples were subsequently normalized by the estimated volume.

The filter cassette was mounted approximately $2.5 \mathrm{~m}$ above the ground. The sampling point is surrounded by buildings, traditional dwelling areas (ger khoroolol), and the combinations of asphalt and unpaved roads.

\subsection{Selection of Samples for XANES Measurements}

For the XANES measurements, six $\mathrm{PM}_{2.5}$ samples and three $\mathrm{PM}_{10-2.5}$ samples were selected for the speciation of two elements of interest $-\mathrm{Cr}$ and $\mathrm{Zn}$. Selections were based on the highest relevance when these elements were found at elevated concentrations. The elemental analysis of the fine and coarse PM samples was performed by means of the PANalytical Epsilon 5 energydispersive X-ray fluorescence (EDXRF) spectrometer at the premises of the Nuclear Science and Instrumentation Laboratory of the International Atomic Energy Agency (IAEA), Seibersdorf, Austria (Gunchin et al., 2019). The spectrometer features various secondary targets, such as $\mathrm{Al}, \mathrm{CaF}_{2}, \mathrm{Fe}$, $\mathrm{Ge}, \mathrm{Zr}, \mathrm{Mo}, \mathrm{Ag}$ and $\mathrm{Al}_{2} \mathrm{O}_{3}$ (Barkla polarization target) which are irradiated by a $600 \mathrm{~W} \mathrm{Sc}-\mathrm{W}$ anode $X$-ray tube. The characteristic $X$-ray radiation emitted by the sample is detected by an $\mathrm{LN}_{2}$-cooled LEGe detector with energy resolution of about $150 \mathrm{eV}$ at $\mathrm{Mn}-\mathrm{K \alpha}(5.89 \mathrm{keV})$.

Fe and Ge secondary targets were used for $\mathrm{Cr}$ and $\mathrm{Zn}$ determination, respectively. Operational conditions for both secondary targets were $75 \mathrm{kV}$ and $8 \mathrm{~mA}$. The live time for each secondary target was set to $300 \mathrm{~s}$. The analysis was performed under vacuum conditions.

The quantification of elements' concentrations was carried out using a calibration performed by measuring thin film single element and compound reference materials. The built-in software of the PANalytical Epsilon 5 was used for spectrum deconvolution, whereas the elemental concentrations were calculated using a sensitivity curve determined from the measured set of reference materials. Thin film approximation was applied. A Standard Reference Material (SRM) of particulate matter on filter media (SRM 2783; NIST, Gaithersburg, MD, USA) was used for validation of the analytical method. The uncertainty of the results were evaluated according to the study of Gutknecht et al. (2010), where the following contributing factors were considered: the peak area statistical uncertainty, the fitting error in the calibration (sensitivity) curve, the quoted uncertainties of the elemental areal densities reported for the standards (5\%), the estimated error due to the omittance of the self-attenuation effect as well as the relative standard deviation of three replicate measurements (reproducibility in operation). A more detailed description of the evaluation of the combined uncertainty of obtained result can be found in Gunchin et al. (2019).

In Fig. 1, the EDXRF results reported as time series of $\mathrm{Zn}$ and $\mathrm{Cr}$ concentrations in $\mathrm{ng} \mathrm{m}^{-3}$ for all measured fine (a) and coarse (b) particulate samples are shown (Gunchin et al., 2019). The sample selection for XANES analysis was based on higher $\mathrm{Zn}$ and $\mathrm{Cr}$ concentration: Those samples are marked with red circles in Fig. 1. The selected six fine samples were collected on 7 Nov, 14 Nov, 5 Dec, 19 Dec 2016 and 5 Jan, 12 Jan 2017 and the selected three coarse samples have collection dates of 7 Nov 2016 and 5 Jan and 12 Jan 2017.

\subsection{XANES Measurement}

X-ray absorption near-edge structure (XANES) spectra were acquired at the XRF IAEA experimental end station (Lubeck et al., 2016) of Elettra Sincrotrone Trieste (Basovizza, Italy). The experimental 

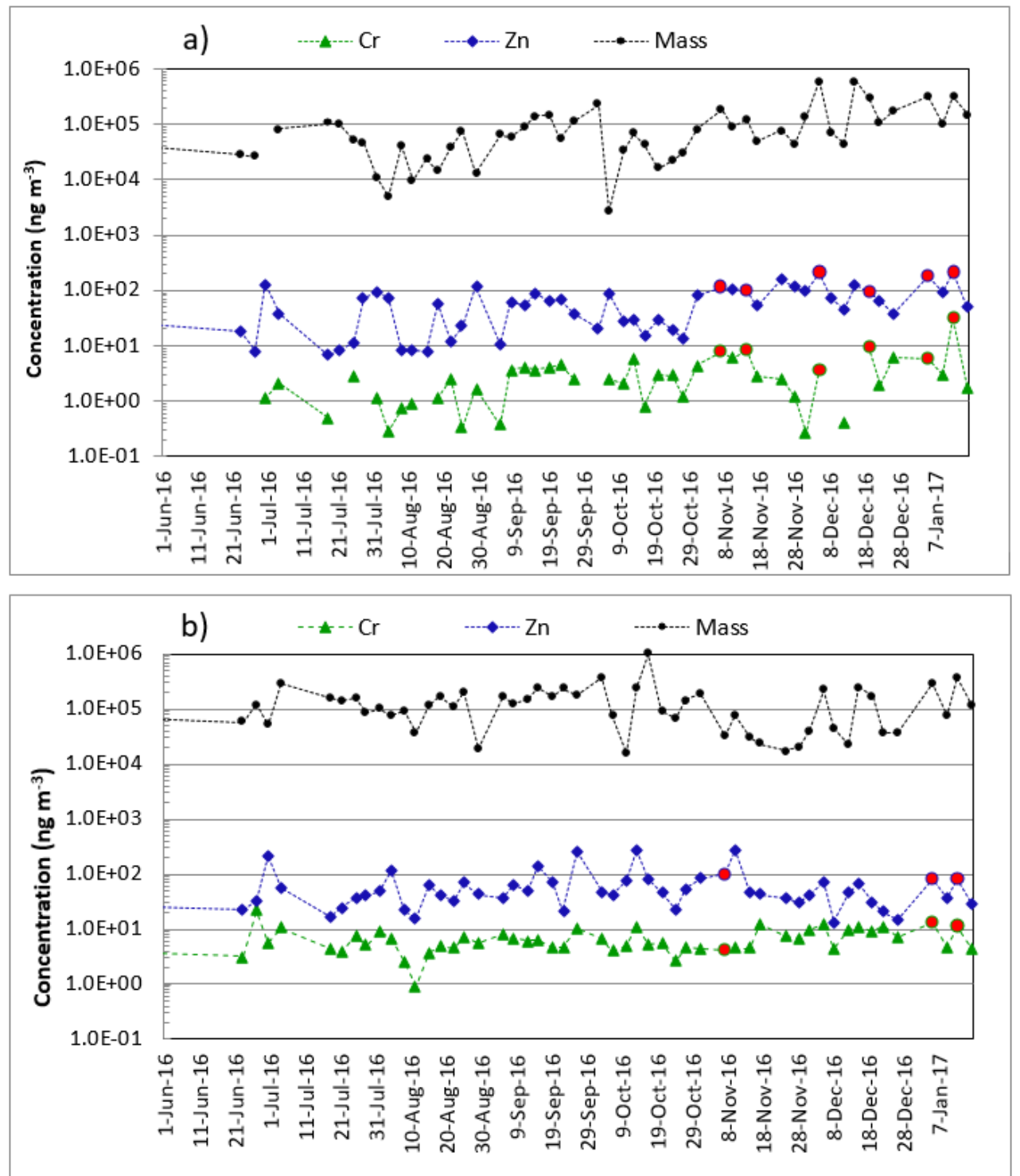

Fig. 1. Time series of $\mathrm{Zn}$ and $\mathrm{Cr}$ concentrations in (a) $P M_{2.5}$ samples (fine) and (b) $P M_{2.5-10}$ samples (coarse) (red points: selected samples for XANES).

set-up is comprised by a $\mathrm{Si}(111)$ double-crystal monochromator, an ultra-thin-window Bruker silicon drift detector ( $30 \mathrm{~mm}^{2}$, energy resolution $135 \mathrm{eV}$ at $\mathrm{Mn}-\mathrm{Ka}$ ), photodiodes and other beam-monitoring devices. The samples were inserted into an ultra-high-vacuum chamber equipped with a multi-axis motorized sample manipulator, which offers the possibility to vary the orientation of the sample surface with respect to the exciting beam direction (Wrobel et al., 2017; Karydas et al., 2018).

The selected PM samples were mounted on Al holders using carbon tape and they were forced to be fixed as flat as possible. For the XANES measurements the samples have been excited under a shallow angle of incidence $\left(\sim 1^{\circ}\right)$. The influence of the angle of incidence on detection limits was investigated by Karydas et al. (2018) using a thin reference material deposited on polycarbonate filter. The grazing incidence geometry provides a larger beam footprint resulting to an increase of the PM analyzed mass and better counting statistics. The specially designed Al holder allows to measure in this geometry without producing parasitic fluorescence and scattered radiation. The comparison of shallow angle excitation geometry on aerosol sample to a conventional $45^{\circ} / 45^{\circ}$ geometry resulted in significantly increased signals $(\sim 10$-fold). XANES spectra with satisfactory good statistics could be therefore collected in a shorter time with the beam irradiating the samples with shallow angle. Energy scans were performed around the K-edges of the two elements of interest (5989 eV for $\mathrm{Cr}$ and $9659 \mathrm{eV}$ for $\mathrm{Zn}$ ) using the $\mathrm{Si}(111)$ monochromator (energy resolution 
of about $1 \mathrm{eV}$ ) and recording the corresponding Ka fluorescence intensity in fluorescence mode. The used energy step size varied between 0.5 (edge region) to $2 \mathrm{eV}$. The measurement time for each energy step varied from 10 to $20 \mathrm{~s}$, depending on the concentration of the element in the PM samples. Two to four repetitions were done for each sample, in order to increase the data quality. $\mathrm{Cr}$ and $\mathrm{Zn}$ metal foils were used for energy calibration of the $\mathrm{Si}(111)$ monochromator.

In the case of chromium, XANES spectra of potassium chromate $\left(\mathrm{K}_{2} \mathrm{CrO}_{4}\right)$, chromium(III) oxide $\left(\mathrm{Cr}_{2} \mathrm{O}_{3}\right)$, potassium dichromate $\left(\mathrm{K}_{2} \mathrm{Cr}_{2} \mathrm{O}_{7}\right)$, nickel-based chromite spinel $\left(\mathrm{NiCr}_{2} \mathrm{O}_{4}\right)$ and trivalent chromium sulfate $\left[\mathrm{Cr}_{2}\left(\mathrm{SO}_{4}\right)_{3}\right]$ were collected as references; for zinc, zinc carbonate $\left(\mathrm{ZnCO}_{3}\right)$, zinc nitrate $\left[\mathrm{Zn}\left(\mathrm{NO}_{3}\right)_{2}\right]$, zinc sulfate monohydrate $\left(\mathrm{ZnSO}_{4} \cdot \mathrm{H}_{2} \mathrm{O}\right)$, zinc silicate/willemite $\left(\mathrm{Zn}_{2} \mathrm{SiO}_{4}\right)$, zinc oxalate $\left(\mathrm{ZnC}_{2} \mathrm{O}_{4}\right)$ and zinc chloride $\left(\mathrm{ZnCl}_{2}\right)$ were used as references. Most of these reference compounds were measured as pressed pellets in transmission mode at the X-ray absorption fine structure (XAFS) beamline of Elettra (Di Cicco et al., 2009).

The obtained spectra were processed with the Athena Demeter software (Ravel and Newville, 2005), which uses a least-squares algorithm to refine the linear combination fit (LFC) of a given number of reference spectra to the measured spectrum. The refining procedure is the following: The sample spectra were initially fit using all of the given reference spectra. After each fitting, any references that accounted for less than $5 \%$ of the total amount of species in the sample were removed from the fitting to eliminate both minor components and erroneous fittings. After this, the sample spectrum was fit again with only the references of the remaining species. This process was repeated until the sample spectrum was described by one or more references each accounting for $5 \%$ or more of the total species. The quality of the fit can be quantified by an error term (R-factor) which indicates the proper choice of standard compounds. Averaging, background removal and normalization of XANES spectra were done by the Athena software.

\section{RESULTS AND DISCUSSION}

\subsection{Speciation of Chromium}

Compositional information derived from LCF suggested that chromium sulfate and chromium oxide are likely present in both the fine and coarse fraction samples. Fig. 2 shows the normalized XANES spectra at the Cr K-edge of the measured fine (a) and coarse (b) sample sets from Ulaanbaatar, together with two reference compounds. Representative XANES spectra of Cr K-edge from the LFC analysis for fine (a) and coarse (b) sample are also illustrated in Fig. 3.
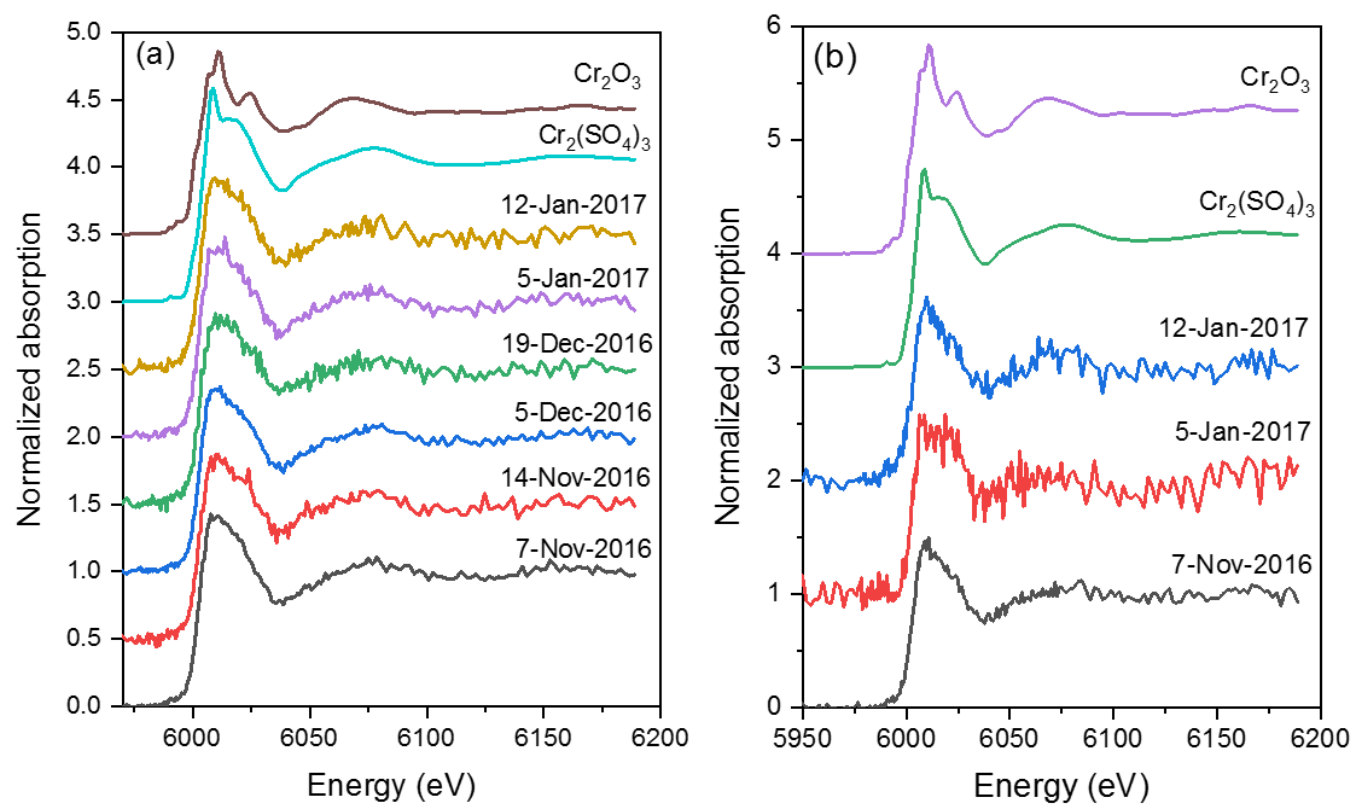

Fig. 2. Cr K-edge XANES spectra of (a) fine and (b) coarse samples; standard spectra of Cr sulfate and $\mathrm{Cr}$ oxide are plotted for comparison. 

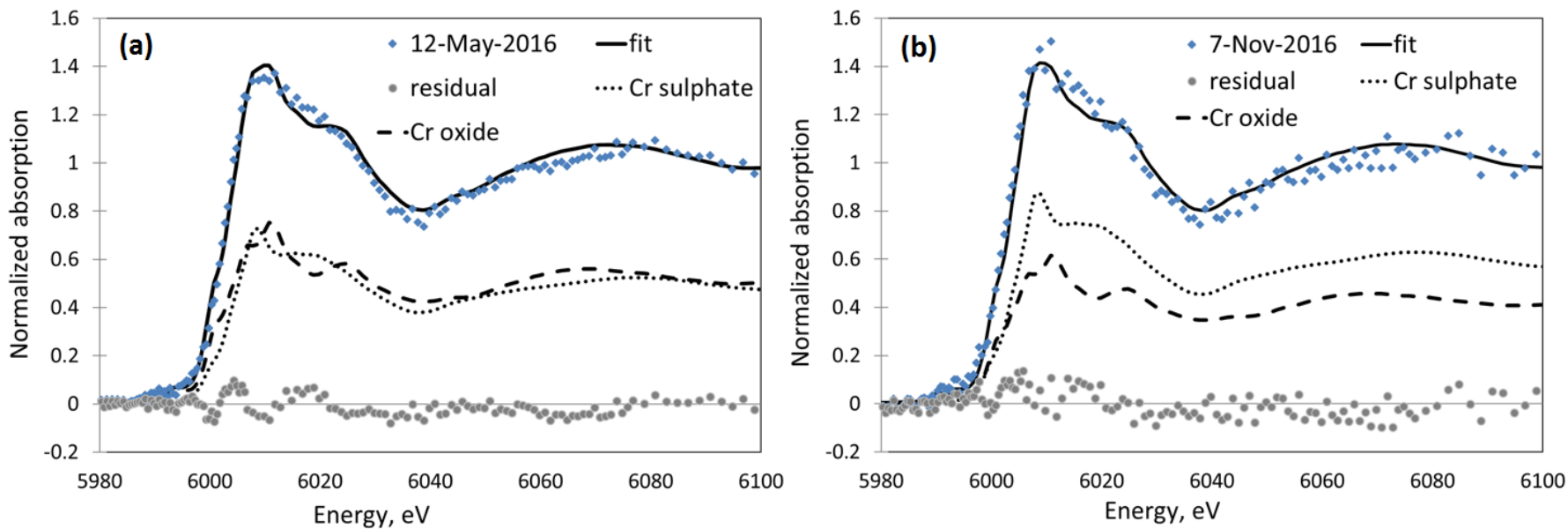

Fig. 3. Representative LCF spectra of the (a) fine and (b) coarse samples for Cr K-edge. The blue dots are the acquired data, while the black line (smooth) is the linear combination fit to the data; the two pecked lines are reference spectra $\left(\right.$ fine: $\mathrm{Cr}_{2}\left(\mathrm{SO}_{4}\right)_{3}$ is $49 \%$ and $\mathrm{Cr}_{2} \mathrm{O}_{3}$ is $51 \%$; coarse: $58 \%$ and $42 \%$, respectively) and the grey dots are the residuals.

The determined relative concentration (or abundance) percentages of chromium sulfate and chromium oxide from XANES measurements, the concentration values of $\mathrm{Cr}$ and $\mathrm{S}$ in the air from EDXRF analyses and the R-factor, which expresses the quality of the fitting for each fine and coarse sample, are reported in Table 1 and Table 2, respectively.

In both fractions it can be noticed that chromium sulfate is a bit more dominant than chromium oxide, except the sample " 5 Dec 2016," which has almost equal contributions of sulfate and oxide, and the sample "12 Jan 2017," where the percentage ratio is inverted. $\mathrm{PM}_{2.5}$ samples are comprised between $49 \%$ and $70 \%$ of chromium sulfate and $30-51 \%$ of chromium oxide. In PM10-2.5 samples, chromium sulfate is contained in the range of $36-93 \%$ and $\mathrm{Cr}$ oxide between $7 \%$ and $64 \%$. There was no clear correlation observed between speciation abundances and concentration values of $\mathrm{Cr}$ and $\mathrm{S}$. The main reason for this might rely on secondary organic aerosol (SOA) and secondary inorganic aerosol (SIA) concentrations in the sample. SOA and SIA are emitted or formed by the oxidation of gas-phase species in the atmosphere (De Gouw and Jimenez, 2009).

The majority (60-70\%) of chromium sources are of anthropogenic origins such as fuel combustions, metallurgical industries, refractory brick production, waste incineration and $\mathrm{Cr}$ containing chemicals (Seigneur and Constantinou, 1995; Werner et al., 2007; Catrambone et al., 2013). The remaining $30 \%$ comes from natural sources like crustal matter and volcanic eruptions

Table 1. Total mass, $\mathrm{Cr}$ speciation, $\mathrm{Cr}$ and $\mathrm{S}$ concentration of the $\mathrm{PM}_{2.5}$ samples.

\begin{tabular}{lllllll}
\hline \multirow{2}{*}{ Sample date } & \multirow{2}{*}{ Mass $\left(\mu \mathrm{g} \mathrm{m}^{-3}\right)$} & \multicolumn{2}{c}{$\mathrm{Cr}$ chemical form (\%) } & \multirow{2}{*}{$\mathrm{R}$-factor } & & \multicolumn{2}{c}{ Concentration (ng m $\left.{ }^{-3}\right)$} \\
\cline { 3 - 4 } & & $\mathrm{Cr}_{2}\left(\mathrm{SO}_{4}\right)_{3}$ & $\mathrm{Cr}_{2} \mathrm{O}_{3}$ & $\mathrm{Cr}$ & $\mathrm{S}$ \\
\hline 07 Nov 2016 & 189 & $59 \pm 5$ & $41 \pm 5$ & 0.0032 & 11.5 & 7040 \\
14 Nov 2016 & 121 & $57 \pm 4$ & $43 \pm 4$ & 0.0022 & 10.0 & 3340 \\
05 Dec 2016 & 597 & $49 \pm 4$ & $51 \pm 4$ & 0.0017 & 7.40 & 12,300 \\
19 Dec 2016 & 301 & $69 \pm 6$ & $31 \pm 6$ & 0.0037 & 12.0 & 5560 \\
05 Jan 2017 & 322 & $57 \pm 5$ & $43 \pm 5$ & 0.003 & 12.0 & 7100 \\
12 Jan 2017 & 315 & $70 \pm 5$ & $30 \pm 5$ & 0.0025 & 36.5 & 11,500 \\
\hline
\end{tabular}

Table 2. Total mass, $\mathrm{Cr}$ speciation, $\mathrm{Cr}$ and $\mathrm{S}$ concentration of the $\mathrm{PM}_{2.5-10}$ samples.

\begin{tabular}{lllllll}
\hline \multirow{2}{*}{ Sample date } & \multirow{2}{*}{ Mass $\left(\mu \mathrm{g} \mathrm{m}^{-3}\right)$} & \multicolumn{2}{c}{$\mathrm{Cr}$ chemical form (\%) } & \multirow{2}{*}{ R-factor } & & \multicolumn{2}{c}{ Concentration (ng m $\left.{ }^{-3}\right)$} \\
\cline { 3 - 4 } & & $\mathrm{Cr}_{2}\left(\mathrm{SO}_{4}\right)_{3}$ & $\mathrm{Cr}_{2} \mathrm{O}_{3}$ & & $\mathrm{Cr}$ & $\mathrm{S}$ \\
\hline 07 Nov 2016 & 63.0 & $58 \pm 5$ & $42 \pm 5$ & 0.0033 & 3.50 & 2460 \\
05 Jan 2017 & 64.0 & $93 \pm 13$ & $7 \pm 12$ & 0.0177 & 12.0 & 1770 \\
12 Jan 2017 & 116 & $36 \pm 9$ & $64 \pm 9$ & 0.0088 & 11.0 & 4560 \\
\hline
\end{tabular}


(Catrambone et al., 2013). The fact that smaller grain sizes of atmospheric particles are mainly generated from anthropogenic sources, as well as the coexistence of $\mathrm{SO}_{4}{ }^{2-}$, may indicate that chromium sulfate is the main $\mathrm{Cr}$ compound of $\mathrm{PM}_{2.5}$ samples. Our previous research has shown that the common primary emission sources of Ulaanbaatar's atmospheric PM are traffic, coal combustion and soil (Gunchin et al., 2019). Due to this fact, chromium sulfate may correspond to anthropogenic combustion sources.

One of the main occurrences of $\mathrm{Cr}$ is the trivalent oxidation state in forms of chromium oxides, such as $\mathrm{Cr}_{2} \mathrm{O}_{3}$. This compound is present in both measured fractioned samples. These results are similar to those reported in the study of Wang et al. (2007), which indicated that the main chemical component of $\mathrm{Cr}$ in PM was chromite and oxides of trivalent chromium, close to iron and steel industrial area. However, it should be noted that due to geographical and climate differences, the results of these works cannot be compared directly. It is worth to mention that $\mathrm{Cr}(\mathrm{VI})$ content, which has high health concern, was not present in the measured samples.

\subsection{Speciation of Zinc}

Four $\mathrm{Zn}$ compounds were identified in the measured samples: zinc sulfate, zinc silicate, zinc chloride and zinc oxalate. Fig. 4 shows the normalized Zn XANES spectra of the measured fine (a) and coarse (b) samples, together with those of the reference compounds. Representative XANES spectra of Zn K-edge from the LFC analysis for fine (a) and coarse (b) sample are illustrated in Fig. 5.

The determined relative concentration (or abundance) percentages of zinc sulfate, zinc silicate and zinc oxalate from XANES measurements; the concentration values of $\mathrm{Zn}, \mathrm{S}$ and $\mathrm{Si}$ in the air from EDXRF analyses; and the R-factor, which expresses the quality of the fitting for each fine and coarse sample, are reported in Table 3 and Table 4, respectively.

In the fine fraction, zinc sulfate and zinc silicate were identified as the major constituents of all measured samples and zinc oxalate accounted for the rest contribution. Sulfur is often used as a tracer for coal burning in source apportionment studies (Davy et al., 2011) and $\mathrm{SO}_{2}$ is produced during combustion processes (Ohta et al., 2006), leading to formation of secondary sulfate particles mainly present in the fine fraction. In Wang et al. (2007), the authors report that Zn exists mainly as $\mathrm{ZnSO}_{4}$ in $\mathrm{PM}_{2.5}$ samples from both industrial and agricultural areas of Shanghai city. Therefore, $\mathrm{Zn}$ in the form of sulfate can originate either directly from a local anthropogenic emission as $\mathrm{ZnSO}_{4}$ or from $\mathrm{Zn}$ originally emitted in other forms that condenses to secondary sulfate particles. Mattielli et al. (2009) reported that zinc is present as a sulfide $(\mathrm{ZnS})$ or carbonate $\left(\mathrm{ZnCO}_{3}\right)$ or as minor constituent of silicate minerals in the natural environment, so that it can be assumed that
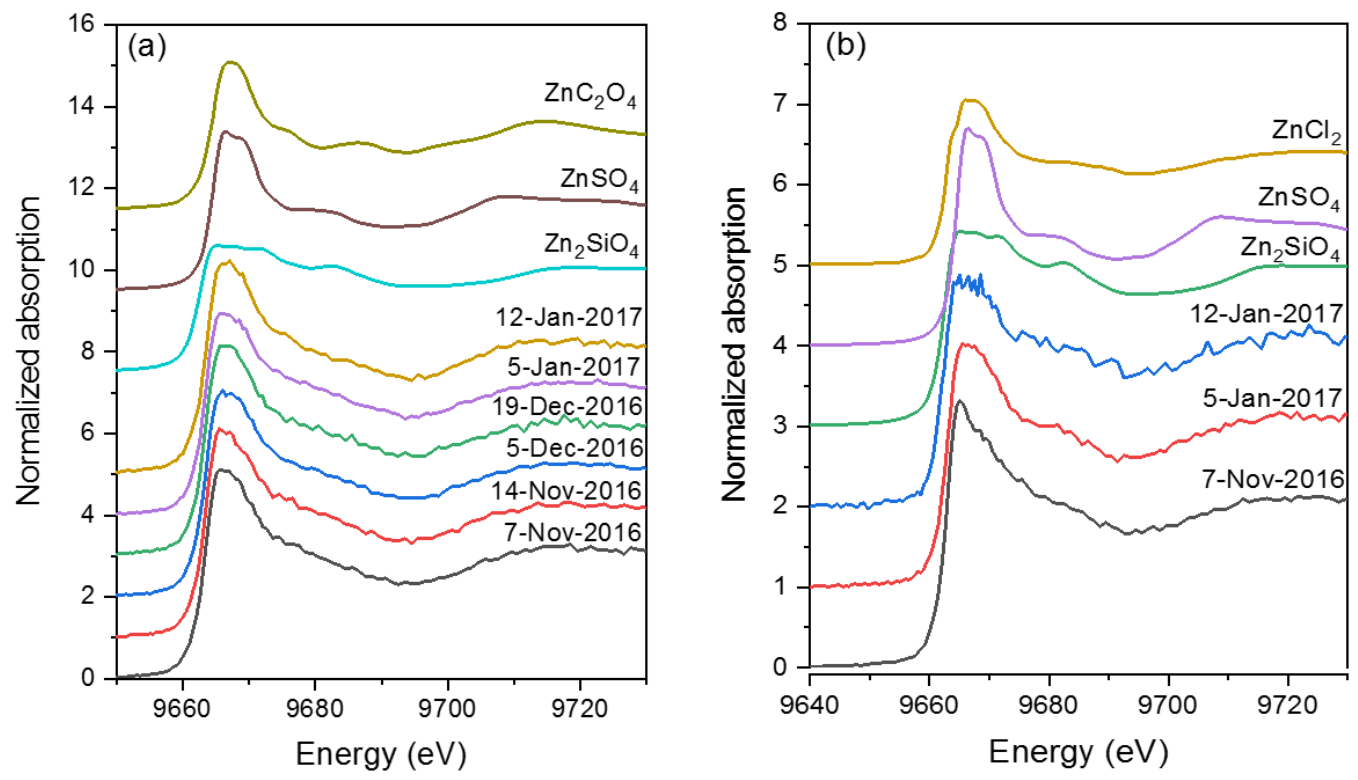

Fig. 4. Zn K-edge XANES spectra on (a) fine and (b) coarse samples and reference spectra of Zn oxalate, $\mathrm{Zn}$ chloride, $\mathrm{Zn}$ sulfate and $\mathrm{Zn}$ silicate are plotted for comparison. 

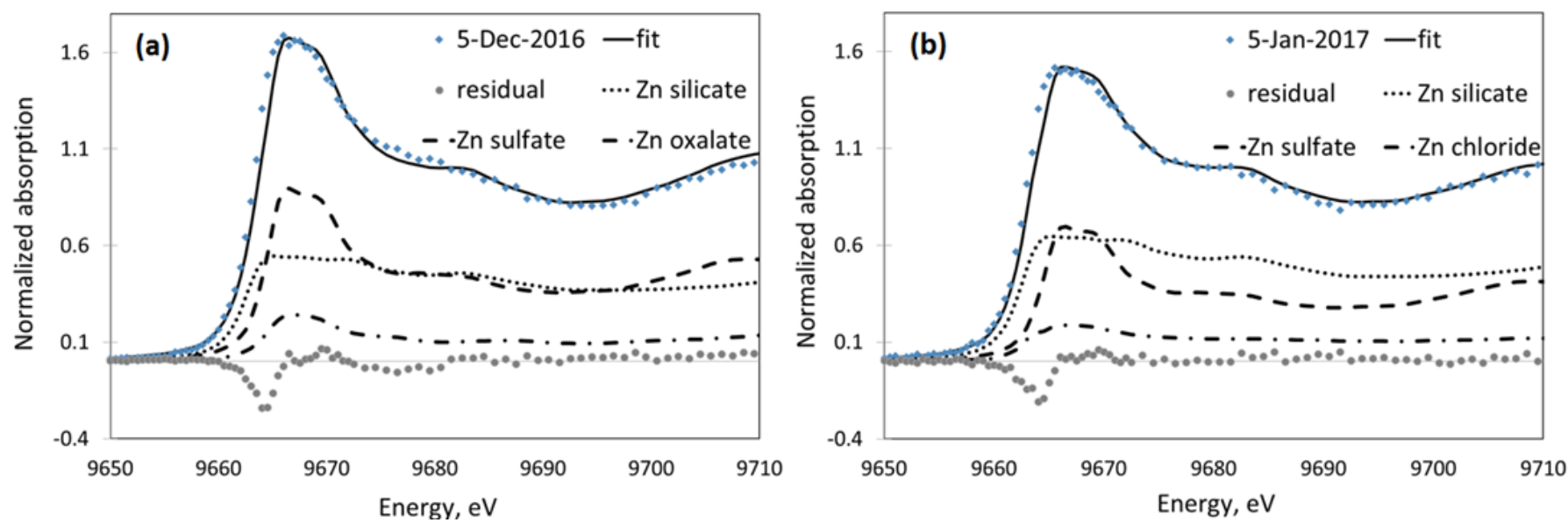

Fig. 5. Representative LCF spectra of the (a) fine and (b) coarse samples for Zn K-edge. The blue dots are the acquired data, while the black line (smooth) is the linear combination fit to the data; the two pecked lines are reference spectra (fine: $\mathrm{ZnSO}_{4}$ is $46 \%$, $\mathrm{Zn}_{2} \mathrm{SiO}_{4}$ is $42 \%$ and $\mathrm{ZnCl}_{2}$ is $12 \%$; coarse: $37 \%, 51 \%$, and $12 \%$, respectively) and the grey dots are the residuals.

Table 3. Total mass, $\mathrm{Zn}$ speciation, $\mathrm{Cr}$ and $\mathrm{S}$ concentration of the $\mathrm{PM}_{2.5}$ samples.

\begin{tabular}{|c|c|c|c|c|c|c|c|c|}
\hline \multirow{2}{*}{ Sample date } & \multirow{2}{*}{ Mass $\left(\mu \mathrm{g} \mathrm{m}^{-3}\right)$} & \multicolumn{3}{|c|}{ Zn chemical form (\%) } & \multirow{2}{*}{ R-factor } & \multicolumn{3}{|c|}{ Concentration $\left(\mathrm{ng} \mathrm{m}^{-3}\right)$} \\
\hline & & $\mathrm{ZnSO}_{4}$ & $\mathrm{Zn}_{2} \mathrm{SiO}_{4}$ & $\mathrm{ZnC}_{2} \mathrm{O}_{4}$ & & $\mathrm{Zn}$ & $\mathrm{S}$ & $\mathrm{Si}$ \\
\hline 07 Nov 2016 & 189 & $47 \pm 7$ & $36 \pm 2$ & $17 \pm 6$ & 0.0043 & 111 & 7040 & 1830 \\
\hline 14 Nov 2016 & 121 & $51 \pm 6$ & $42 \pm 2$ & $7 \pm 5$ & 0.0041 & 94.0 & 3340 & 633 \\
\hline 05 Dec 2016 & 597 & $46 \pm 5$ & $42 \pm 2$ & $12 \pm 5$ & 0.0026 & 202 & 12,300 & 616 \\
\hline 19 Dec 2016 & 301 & $40 \pm 6$ & $41 \pm 2$ & $19 \pm 6$ & 0.0035 & 92.0 & 5560 & 636 \\
\hline 05 Jan 2017 & 322 & $47 \pm 6$ & $47 \pm 2$ & $6 \pm 5$ & 0.0035 & 173 & 7100 & 544 \\
\hline 12 Jan 2017 & 315 & $41 \pm 5$ & $35 \pm 2$ & $24 \pm 5$ & 0.0029 & 210 & 11,500 & 1400 \\
\hline
\end{tabular}

Table 4. Total mass, $\mathrm{Zn}$ speciation, $\mathrm{Cr}$ and $\mathrm{S}$ concentration of the $\mathrm{PM}_{2.5-10}$ samples.

\begin{tabular}{|c|c|c|c|c|c|c|c|c|c|}
\hline \multirow{2}{*}{ Sample date } & \multirow{2}{*}{ Mass $\left(\mu \mathrm{g} \mathrm{m}^{-3}\right)$} & \multicolumn{3}{|c|}{ Zn chemical form (\%) } & \multirow{2}{*}{ R-factor } & \multicolumn{4}{|c|}{ Concentration $\left(\mathrm{ng} \mathrm{m}^{-3}\right)$} \\
\hline & & $\mathrm{ZnSO}_{4}$ & $\mathrm{Zn}_{2} \mathrm{SiO}_{4}$ & $\mathrm{ZnCl}_{2}$ & & $\mathrm{Zn}$ & $\mathrm{S}$ & $\mathrm{Si}$ & $\mathrm{Cl}$ \\
\hline 07 Nov 2016 & 63.0 & $35 \pm 5$ & $48 \pm 8$ & $17 \pm 12$ & 0.0071 & 100 & 2450 & 3100 & 86.0 \\
\hline 05 Jan 2017 & 64.0 & $37 \pm 3$ & $51 \pm 4$ & $12 \pm 6$ & 0.0021 & 79.0 & 1770 & 2140 & 2000 \\
\hline 12 Jan 2017 & 116 & $7 \pm 4$ & $54 \pm 5$ & $39 \pm 8$ & 0.0047 & 81.0 & 4560 & 6340 & 1130 \\
\hline
\end{tabular}

zinc silicate could be related to crustal sources, or dust resuspension due to traffic. According to the study of Furukawa and Takahashi (2011), zinc oxalate can be the main oxalate species considering its high concentration in aerosols and the presence of this compound particularly in finer particles. Zinc oxalate is an important component of secondary organic aerosol and its formation in the atmosphere can be obtained in several different ways. However, the formation of aqueous phase on the particle surface is dominant; therefore, $\mathrm{Zn}$ oxalate is found to be mainly present in the fine fractions.

In the coarse fraction, $\mathrm{Zn}$ is contained mostly as silicates which may be a clear indication of crustal source. The second identified constituent in the measured samples was zinc sulfate. Sulfate forms of $\mathrm{Zn}$ are usually pronounced and characteristic in winter season. Since all measured samples were taken in mid-winter months, this compound could also be referred to the combustion source. The residual contribution is zinc chloride. In their study, Furukawa and Takahashi (2011) also show that $\mathrm{Zn}$ chloride was observed only in the coarser particles, having no relation with the seasons. Nevertheless, Zn chloride (along with Zn silicate) was found as significant component of $\mathrm{Zn}$ in fly ash particles sampled directly from the stack of coal and municipal solid waste (Cai et al., 2015; Yu et al., 2009). Origins and formulation of this compound in atmospheric particles can be related to anthropogenic sources. There was finally no clear correlation between speciation abundances and concentration values of $\mathrm{Zn}, \mathrm{S}, \mathrm{Si}$ and $\mathrm{Cl}$. 
Using a small incidence angle for the synchrotron radiation, we performed XANES spectroscopy on size-fractionated atmospheric particulate matter (viz., $\mathrm{PM}_{2.5}$ and $\mathrm{PM}_{2.5-10}$ ) collected on polycarbonate filters in the city of Ulaanbaatar, Mongolia. We characterized the chemical states of the $\mathrm{Cr}$ and $\mathrm{Zn}$ in the $\mathrm{PM}_{2.5}$ and $\mathrm{PM}_{2.5-10}$ and selected suitable PM samples for the XANES spectroscopy through EDXRF analysis. Our results revealed that $\mathrm{Cr}$ mainly existed as $\mathrm{Cr}_{2}\left(\mathrm{SO}_{4}\right)_{3}$ and $\mathrm{Cr}_{2} \mathrm{O}_{3}$ in both the fine and the coarse fraction. However, the abundances of these constituents varied and showed no direct relation with the concentrations of the airborne $\mathrm{Cr}$ or S. Additionally, we only found $\mathrm{Zn}$ in its divalent chemical forms. Although both $\mathrm{PM}$ fractions contained abundances of sulfate $\left(\mathrm{ZnSO}_{4}\right)$ and silicate $\left(\mathrm{Zn}_{2} \mathrm{SiO}_{4}\right)$, only the fine mode contained $\mathrm{Zn}$ oxalate $\left(\mathrm{ZnC}_{2} \mathrm{O}_{4}\right)$, whereas only the coarse mode contained $\mathrm{Zn}$ chloride $\left(\mathrm{ZnCl}_{2}\right)$. As with $\mathrm{Cr}$, the relative concentrations of these Zn species exhibited no correlations with the levels of the airborne Zn, S or Si. Finally, anthropogenic sources, such as combustion products and traffic-related resuspended road dust, primarily contributed the $\mathrm{Cr}$ and $\mathrm{Zn}$ species detected in our PM samples.

These findings shed light on the physiochemical characteristics and potential sources of metallic constituents in atmospheric fine- and coarse-mode PM, thereby supporting future studies on mixture toxicity and synergistic effects that, in contrast to the current efforts, are not based solely on the total elemental concentrations.

\section{ACKNOWLEDGEMENT}

This project was funded by Mongolian Foundation for Science and Technology and supported in part by the International Atomic Energy Agency (IAEA) through the Regional Cooperation Agreement Program RAS/7/023. Moreover, this work has been supported through the joint IAEA and the International Centre for Theoretical Physics (ICTP) Sandwich Training Educational Program (STEP) fellowship C6/MON/15001 granted to Gerelmaa Gunchin. Ms. Gunchin expresses her gratitude to IAEA's former officials Dr. Andreas Karydas and Dr. Iain Darby, XRF end station staffs of Elettra as well as XRF group of Atominstitut, TU Wien, for their support and guidance throughout the beamtime experiment and data evaluations.

\section{REFERENCES}

Ashley, K., Howe, A.M., Demange, M., Nygren, O. (2003). Sampling and analysis considerations for the determination of hexavalent chromium in workplace air. J. Environ. Monit. 5, 707-716. https://doi.org/10.1039/B306105C

Boman, C., Nordin, A., Boström, D., Öhman, M. (2004). Characterization of inorganic particulate matter from residential combustion of pelletized biomass fuels. Energy Fuels 18, 338-348. https://doi.org/10.1021/ef034028i

Cai, X., Huang, Q., Alhadj-mallah, M., Chi, Y., Yan, J. (2015). Characterization of zinc vapor condensation in fly ash particles using synchrotron X-ray absorption spectroscopy. J. Zhejiang Univ. Sci. A 16, 70-80. https://doi.org/10.1631/jzus.A1400178

Catrambone, M., Canepari, S., Perrino, C. (2013). Determination of $\mathrm{Cr}(\mathrm{III}), \mathrm{Cr}(\mathrm{VI})$ and total chromium in atmospheric aerosol samples. E3S Web Conf. 1 07005. https://doi.org/10.1051/ e3sconf/20130107005

Cruz, A.M.J., Sarmento, S., Almeida, S.M., Silva, A.V., Alves, C., Freitas, M.C., Wolterbeek, H. (2015). Association between atmospheric pollutants and hospital admissions in Lisbon. Environ. Sci. Pollut. Res. 22, 5500-5510. https://doi.org/10.1007/s11356-014-3838-z

Davy, P.K., Gunchin, G., Markwitz, A., Trompetter, W.J., Barry, B.J., Shagjjamba, D., Lodoysamba, S. (2011). Air particulate matter pollution in Ulaanbaatar, Mongolia: Determination of composition, source contributions and source locations. Atmos. Pollut. Res. 2, 126-1307. https://doi.org/10.5094/APR.2011.017

Dayan, A.D., Paine, A.J. (2000). Mechanisms of chromium toxicity, carcinogenicity and allergenicity: Review of the literature from 1985 to 2000. Hum. Exp. Toxicol. 20, 439-451. 
https://doi.org/10.1191/096032701682693062

De Gouw, J., Jimenez, J.L. (2009). Organic aerosols in the Earth's atmosphere. Environ. Sci. Technol. 43, 7614-7618. https://doi.org/10.1021/es9006004

Di Cicco, A., Aquilanti, G., Minicucci, M., Principi, E., Novello, N., Cognigni, A., Olivi, L. (2009). Novel XAFS capabilities at ELETTRA synchrotron light source. J. Phys. Conf. Ser. 190, 012043. https://doi.org/10.1088/1742-6596/190/1/012043

Fittschen, U.E.A. (2014). Strategies for ambient aerosols characterization using synchrotron X-ray fluorescence: A review. Spetrosc. Eur. 26, 10-14.

Furukawa, T., Takahashi, Y. (2011). Oxalate metal complexes in aerosol particles: Implications for the hygroscopicity of oxalate-containing particles. Atmos. Chem. Phys. 11, 4289-4301. https://doi.org/10.5194/acp-11-4289-2011

Galbreath, K.C., Zygarlicke, C.J., Toman, D.L., Huggins, F.E., Huffman, G.P. (1994). Nickel and chromium speciation of residual oil combustion ash. Combust. Sci. Technol. 134, 243-262. https://doi.org/10.1080/00102209808924135

Goodzari, F., Huggins, F.E., Sanei, H. (2008). Assessment of elements, speciation of As, $\mathrm{Cr}$, Ni and emitted $\mathrm{Hg}$ for a Canadian power plant burning bituminous coal. Int. J. Coal Geol. 74, 1-12. https://doi.org/10.1016/j.coal.2007.09.002

Gunchin, G., Manousakas, M., Osan, J., Karydas, A.G., Eleftheriadis, K., Lodoysamba, S., Shagjjamba, D., Migliori, A., Padilla-Alvarez, R., Streli, C., Darby, I. (2019). Three-year long source apportionment study of airborne particles in Ulaanbaatar using $X$-ray fluorescence and positive matrix factorization. Aerosol Air Qual. Res. 19, 1056-1067. https://doi.org/10.4209/aaqr.2018.09.0351

Huggins, F.E., Huffman, G.P., Linak, W.P., Miller, C.A. (2004). Quantifying hazardous species in particulate matter derived from fossil fuel combustion. Environ. Sci. Technol. 38, 1836-1842. https://doi.org/10.1021/es0348748

Huggins, F.E., Huffman, G.P., Robertson, J.D. (2000). Speciation of elements in NIST particulate matter SRMs 1648 and 1650. J. Hazard. Mater. 74, 1-23. https://doi.org/10.1016/S03043894(99)00195-8

Karydas A.G., Czyzycki, M., Leani, J.J., Migliori, A., Osan, J., Bogovac, M., Wrobel, P., Vakula, N., Padilla-Alvarez, R., Menk, R.H., Gol, M.G., Antonelli, M., Tiwari, M.K., Caliri, C., Vogel-Mikuš, K., Darby, I., Kaiser, R.B. (2018). An IAEA multi-technique X-ray spectrometry endstation at Elettra Sincrotrone Trieste: Benchmarking results and interdisciplinary applications. J. Synchrotron Rad. 25, 189-203, https://doi.org/10.1107/S1600577517016332

Lubeck, J., Bogovac, M., Boyer, B., Detlefs, B., Eichert, D., Fliegauf, R., Grötzsch, D., Holfelder, I., Hönicke, P., Jark, W., Kaiser, R.B., Kanngießer, B., Karydas, A.G., Leani, J.J., Lépy, M.C., Lühl, L., Ménesguen, Y., Migliori, A., Müller, M., Pollakowski, B., et al. (2016). A new generation of X-ray spectrometry UHV instruments at the SR facilities BESSY II, ELETTRA and SOLEIL. AIP Conf. Proc. 1741, 030011. https://doi.org/10.1063/1.4952834

Maenhaut, W., Francois, F., Cafmeyer, J. (1993). The GENT stacked filter unit sampler for collection of atmospheric aerosols in two size fractions. Report No. NAHRES-19, International Atomic Energy Agency, Vienna, pp. 249-263.

Matsui, Y., Sakai, N., Tsuda, A., Terada, Y., Takaoka, M., Fujimaki, H., Uchiyama, I. (2009). Tracking the pathway of diesel exhaust particles from the nose to the brain by X-ray fluorescence analysis. Spectrochim. Acta Part B 64, 796-801. https://doi.org/10.1016/j.sab.2009.06.017

Mattielli, N., Petit, J.J., Deboudt, K., Flament, P., Perdrix, E., Taillez, A., Rimetz-Planchon, J., Weis, D. (2009). $Z n$ isotope study of atmospheric emissions and dry depositions within a $5 \mathrm{~km}$ radius of a $\mathrm{Pb}-\mathrm{Zn}$ refinery. Atmos. Environ. 43, 6. https://doi.org/10.1016/j.atmosenv.2008.11.030

Ohta, A., Tsuno, H., Kagi, H., Kanai, Y., Nomura, M., Zhang, R., Terashima, S., Imai, I. (2006). Chemical compositions and XANES speciations of Fe, $\mathrm{Mn}$ and $\mathrm{Zn}$ from aerosols collected in China and Japan during dust events. Geochem. J. 40, 363-376. https://doi.org/10.2343/geochemj.40.363

Osán, J, Meirer, F., Groma, V., Török, S., Ingerle, D., Streli, C., Pepponi, G. (2010). Speciation of copper and zinc in size-fractionated atmospheric particulate matter using total reflection mode X-ray absorption near-edge structure spectrometry. Spectrochim. Acta, Part B 65, 10081013, ISSN 0584-8547, https://doi.org/10.1016/j.sab.2010.11.002

Pettine, M., Capri, S. (2005). Digestion treatments and risks of $\mathrm{Cr}(\mathrm{III})-\mathrm{Cr}(\mathrm{VI})$ interconversions during $\mathrm{Cr}(\mathrm{VI})$ determination in soils and sediments - A review. Anal. Chim. Acta 540, 231-238. https://doi.org/10.1016/j.aca.2005.03.040 
Ravel, B., Newville, M. (2005). ATHENA, ARTEMIS, HEPHAESTUS: Data analysis for X-ray absorption spectroscopy using IFEFFIT. J. Synchrotron Radiat. 12, 537-54. https://doi.org/10.1107/S0909 049505012719

Roberts, D., Nachtegaal, M., Sparks, D.L. (2005). Speciation of Metals in Soils, in Tabatabai, M. Sparks, D. (Eds.), Chemical Processes in Soils, John Wiley \& Sons, Ltd, pp. 619-654. https://doi.org/10.2136/sssabookser8.c13

Seigneur, C., Constantinou, E. (1995). Chemical kinetic mechanism for atmospheric chromium. Environ. Sci. Technol. 29, 222-231. https://doi.org/10.1021/es00001a029

Shaltout, A., Harfouche, M., Ahmed, S., Czyzycki, M., Karydas, A. (2017). Synchrotron radiation total reflection X-ray fluorescence (SR-TXRF) and X-ray absorption near edge structure (XANES) of fractionated air particulates collected from Jeddah, Saudi Arabia. Microchem. J. 137, 78-84. https://doi.org/10.1016/j.microc.2017.10.001

Sinclair, A H., Edgerton, E. S., Wyzga, R., Tolsma, D. (2010). A two-time-period comparison of the effects of ambient air pollution on outpatient visits for acute respiratory illnesses. J. Air Waste Manage. Assoc. 60, 163-175. https://doi.org/10.3155/1047-3289.60.2.163

Unceta, N., Séby, F., Malherbe, J., Donard, O.F.X. (2010). Chromium speciation in solid matrices and regulation: A review. Anal. Bioanal. Chem. 397, 1097-1111. https://doi.org/10.1007/s002 16-009-3417-1

Wang, Y., Li, A., Zhan, Y., Wei, L., Li, Y., Zhang, G., Xie, Y., Zhang, J., Zhang, Y., Shan, Z. (2007). Speciation of elements in atmospheric particulate matter by XANES. J. Radioanal. Nucl. Chem. 273, 247-251. https://doi.org/10.1007/s10967-007-0743-7

Werner, M.L., Nico, P.S., Marcus, M.A., Anastasio, C. (2007). Use of micro-XANES to speciate chromium in airborne fine particles in the Sacramento Valley. Environ. Sci. Technol. 41, 49194924. https://doi.org/10.1021/es070430q

Wrobel, P.M., Bogovac, M., Sghaier, H., Leani, J.J., Migliori, A., Padilla-Alvarez, R., Czyzycki, M., Osan, J., Kaiser, R.B., Karydas, A.G. (2016). LabVIEW interface with Tango control system for a multi-technique $X$-ray spectrometry IAEA beamline end-station at Elettra Sincrotrone Trieste. Nucl. Instrum. Methods Phys. Res., Sect. A 833, 105-109. https://doi.org/10.1016/j.nima.201 6.07.030

Yu, M., Tian, S., Chu, W., Chen, D., Wang, Q., Wu, Z. (2009). Speciation of zinc in secondary fly ashes of municipal solid waste at high temperatures. J. Synchrotron Radiat. 16, 528-532. https://doi.org/10.1107/S0909049509020032 